RUNNING HEAD: Workaholics' motivation

\title{
Understanding Workaholics' Motivations: A Self-Determination Perspective
}

\author{
Anja Van den Broeck ${ }^{1,2}$, Bert Schreurs ${ }^{3}$, Hans De Witte ${ }^{2}$, \\ Maarten Vansteenkiste ${ }^{4}$, Filip Germeys ${ }^{1}$, Wilmar Schaufeli ${ }^{5}$ \\ ${ }^{1}$ HUBrussel, Belgium \\ ${ }^{2}$ KULeuven, Belgium \\ ${ }^{3}$ Maastricht University School of Business and Economics \\ ${ }^{4}$ Ghent University, Belgium \\ ${ }^{5}$ Utrecht University, The Netherlands
}

Corresponding Author: Anja Van den Broeck, Stormstraat 2, 1000 Brussel, Belgium.

Email: Anja.vandenbroeck@hubrussel.be

Acknowledgements: The first author's contribution was supported by a grant from the Fund for Scientific Research Flanders (FWO-Vlaanderen). We would like to thank Willy Lens and Tinne Vander Elst for their helpful comments on earlier versions of this article. 


\begin{abstract}
In order to explain the diverging well-being outcomes of workaholism, this study aimed to examine the motivational orientations that may fuel the two main components of workaholism (i.e. working excessively and working compulsively). Drawing on SelfDetermination Theory, both autonomous and controlled motivation were suggested to drive excessive work, which therefore was expected to relate positively to both wellbeing (i.e. vigor) and ill-health (i.e. exhaustion). Compulsive work, in contrast, was hypothesized to originate exclusively out of controlled motivation and therefore to only associate positively with ill-being. Structural equation modeling in a heterogeneous sample of Belgian white-collar workers $(N=370)$ confirmed that autonomous motivation associated positively with excessive work, which then related positively to vigor. Controlled motivation correlated positively with compulsive work, which therefore related positively with exhaustion. The hypothesized path from controlled motivation to exhaustion through excessive work was not corroborated. In general, the findings suggest that primarily compulsive work yields associations with ill-being, since it may stem from a qualitatively inferior type of motivation.
\end{abstract}

KEY WORDS: Work Related Well-being, Quality of Motivation, Human Resources Management, Occupational Health, Europe, White Collar Workers 


\section{Understanding Workaholics' Motivations: A Self-Determination Perspective}

The use of flexible work and the recent development in technology gradually blur the boundaries between work and home. Accordingly, employees may experience increasing difficulty in disengaging from work and therefore turn into workaholics (Porter, 2004; Sparks, Faragher, \& Cooper, 2001). Although workaholism has become a regular topic of discussion in the popular press (Burke, Matthiesen, \& Pallesen, 2006; Taris, Schaufeli, \& Verhoeven, 2005), scholarly research has only recently started clarifying the concept and detailing its consequences (e.g. Ng, Sorensen, \& Feldman, 2007). In this literature, consensus seems to be growing that workaholism may be defined by two core characteristics: working an excessive amount of time and having a compulsive drive to work (Ng et al., 2007; Schaufeli, Taris, \& Bakker, 2006, 2008). However, divergent results have been reported for the relations between these core components of workaholism and employees' well-being (McMillan, O’Driscoll, Marsh, \& Brady, 2001). The present study aims to shed light on these findings by examining employees' motivation underlying the tendencies to work excessively and to work compulsively.

Although various authors have stressed the importance of workaholics' motivation, to date, little research has been conducted to advance the understanding of this phenomenon from a theoretical point of view (McMillan et al., 2001; Schaufeli, Shimazu, \& Taris, 2009). Drawing on Self-Determination Theory (SDT; Deci \& Ryan, 2000, Gagné \& Deci, 2005), we suggest that the tendencies to work excessively and 
compulsively may be fuelled by qualitative different types of motivation and therefore yield divergent associations with employees' well-being. Before detailing these different types of motivation, we first elaborate upon the concept of workaholism.

\section{Workaholism}

In the academic literature, various definitions and conceptualizations of workaholism have emerged (e.g., Robinson, 1999; Spence \& Robbins, 1992). Originally, workaholism was defined as 'the compulsion or the uncontrollable need to work incessantly' (Oates, 1971, p. 11). In line with this definition, workaholism can be defined by two characteristics: working excessively and working compulsively (Schaufeli et al., 2006, 2008).

First, working excessively pertains to actual behavior: Workaholics spend a great deal of time on work related activities when given the discretion to do so (Snir \& Harpaz, 2006; Snir \& Zohar, 2008), up to 50 hours a week (Brett \& Stroh, 2003; Buelens \& Poelmans, 2004; Burke, 2001). As such, they work beyond what is reasonably required to meet the expectations of colleagues or organizational demands (Scott, Moore, \& Miceli, 1997). Spending much time working, herein labeled as working excessively, figures in about all conceptualizations of workaholism. Spence and Robins (1992), for example, included work involvement, while McMillan and colleagues (2001) note that workaholism is evidenced by the tendency to work anytime at any place. People may, however, work long hours for a variety of reasons without necessarily being addicted to work, for example because they need to meet economic demands or deadlines (Schaufeli, Taris, \& Van Rhenen, 2007). In addition to working long hours, workaholism is therefore 
also characterized by another tendency: the inner compulsion to work.

This second component, i.e. working compulsively (Schaufeli et al., 2006), closely resembles the drive to work (Spence \& Robbins, 1992) and the personal reluctance to disengage from work (McMillan et al., 2001) previously ascribed to workaholics. In general, these labels refer to workaholics' uncontrollable preoccupation with working (Robinson, 1999). Workaholics are obsessed with work activities: They persistently and frequently think about work, even when not working (Scott et al., 1997). The tendency to work compulsively is cognitive - rather than behavioral - in nature, such that the syndrome of workaholism consists of overlapping yet complementary aspects: A behavioral component (i.e. working excessively) and a cognitive component (i.e. working compulsively; Schaufeli et al., 2007).

Drawing on Spence and Robbins' (1992) tripartite model of workaholism, some scholars have argued that workaholism also contains an affective dimension: Work enjoyment (e.g., Burke et al., 2006). Others have contested this view (e.g., Ng et al., 2007). Schaufeli et al. (2007) for instance, make a strong case that hardworking people who highly enjoy work closely resemble engaged workers, with work engagement being conceptually and empirically distinct from workaholism. Accordingly, herein, the conceptualization of workaholism includes only two components, working excessively and working compulsively.

In general, workaholism is assumed to undermine employees' well-being ( $\mathrm{Ng}$ et al., 2007). Empirical research has indeed shown that workaholics, relative to nonworkaholics, generally report more ill-health as indexed by job stress, burnout, and 
negative affect, and exhibit lower levels of well-being in terms of job and life satisfaction (e.g., Aziz \& Zickar, 2006; Burke \& Matthiesen, 2004; Taris et al., 2005). However, results are not consistent. McMillan and O'Driscoll (2004) as well as Snir and Zohar (2007), for example, found no differences between workaholics and non-workaholics in terms of mental health and positive affect.

The conflicting results may in part be explained by the different conceptualizations of workaholism: While some authors included work enjoyment in the definition of workaholism, others did not. More generally, it seems that the different components of workaholism may exert differential influences on employees' well-being (Burke, 1999; McMillan \& O’Driscoll, 2004, Scott et al., 1997). This possibility is often ignored, especially in studies using composite workaholism scores (Burke \& Matthiesen, 2004) or comparing different types of workaholics (Aziz \& Zickar, 2006).

Regarding workaholics defined as excessive and compulsive workers, research has evidenced that the cognitive, compulsive tendency mainly drives the health-impairing effects of being a workaholic (see also McMillan et al., 2001). The results concerning the behavioral component of excessive work are inconclusive. While some scholars found negative associations between working long hours and employees' well-being (e.g., Schaufeli, et al., 2007; Taris, Ybema, Beckers, Verheijden, Geurts, \& Kompier, in press), others reported no such association (Taris, Geurts, Schaufeli, Blonk, \& Lagerveld, 2008) or even positive relations between excessive work and well-being (Kinnunen, Feldt, \& Mäkikangas, 2008). Tellingly, a large-scale study suggested that overtime in itself may not be health-impairing. Instead, other conditions such as the quality of work may 
account for the suggested negative associations between overtime and employees' health (Beckers, van der Linden, Smulders, Kompier, van Veldhoven, \& van Yperen, 2004).

The current study aims to advance the understanding of the relations between working excessively, working compulsively and employees' well-being, which is operationalized in terms of exhaustion and vigor, which may be considered among the core components of burnout and work engagement, respectively (Demerouti, Mostert, \& Bakker, 2010). Exhaustion is said to result from intensive physical, affective and/or cognitive strain (Maslach, Schaufeli, \& Leiter, 2001). Vigor, by contrast, is characterized by high levels of energy, mental resilience, persistence and the willingness to invest effort in one's job (Schaufeli, Salanova, González-Romá, \& Bakker, 2002). It represents a eudaimonic aspect of work-related well-being, which goes beyond mere pleasure or positive feelings (Ryan \& Deci, 2001).

Vigor and exhaustion may be regarded as complementary, non-reducible aspects of employees' well-being and ill-health, respectively (Demerouti et al., 2010). Both aspects may co-exist for workaholics as follows: By working long hours and being unable to disengage from work, workaholics may on the one hand lack sufficient time and opportunity to recover from work. The resulting continuous high state of preparedness may increasingly wear out workaholics' energy and eventually result in exhaustion (Schaufeli et al., 2008; Taris et al. , 2008). Being immersed in one's work can, on the other hand, also be psychologically rewarding in and of itself. Brown and colleagues (Brown, Cron, \& Slocum, 1997), for example, found a direct positive effect of effort investment on task satisfaction. Similarly, in a within-person study, Fisher and 
Noble (2004) found that exerting effort was positively associated with positive emotions. Hence, it seems that sheer effort or knowing that one has given one's best culminates in a state of fulfillment and vigor.

Previous research has indicated that burnout and work engagement may co-exist (De Witte \& De Cuyper, 2003). This seemingly contradictory finding may be reconciled by taking into account the temporal dynamics underlying negative (i.e. exhaustion) and positive (i.e. vigor) states of mind. When feeling energetic and enthused, individuals may exert high levels of effort, and therefore become exhausted (Maslach et al., 2001). After a period of recovery, the previous satisfactory experience of exerting effort may then trigger a new cycle of effort investment. Alternatively, rather than alternating experiences, exhaustion and vigor may also co-exist in the continuous flow of employees' emotional life: Either exhaustion or vigor may momentary come to the fore, depending on employee's conscientious focus of attention (Barrett, Mesquita, Ochsner, \& Gross, 2007).

Although it goes beyond the scope of this study to examine the dynamic interplay of exhaustion and vigor as a response to working excessively and compulsively, based on the rationale presented above, we expect particularly working compulsively to be healthimpairing and, accordingly, to relate positively to exhaustion. Excessive work, in contrast, might yield both positive and negative associations with employees' well-being, and hence relate positively to both exhaustion and vigor, depending on the motivation driving the excessive work behavior. Self-Determination Theory (SDT; Deci \& Ryan, 2000) might shed light on this underlying motivation. 


\section{A Self-Determination Perspective on Motivation}

Most motivational theories (e.g., Vroom, 1964) consider motivation from a quantitative point of view. They conceive the degree to which individuals are motivated (high or low) as a crucial predictor of their well-being and performance. According to this view, workaholics would experience enhanced well-being and function optimally, as they are highly motivated employees (Mudrack \& Naughton, 2001; Ng et al., 2007). SelfDetermination Theory (SDT; Deci \& Ryan, 2000, Gagné \& Deci, 2005), however, maintains that besides the quantity or intensity of motivation, also the quality or type of motivation matters. In this regard, SDT considers it important whether individuals experience the reason for behavioral engagement as part of their own. Herein, SDT builds upon the notion of external or internal locus of causality as previously defined by deCharms (1968).

A qualitative less optimal type of motivation, labeled as controlled motivation, occurs when individuals experience an external locus of causality; that is when they consider the reason to engage in a particular activity outside oneself (Deci \& Ryan, 2000). In this case, they have not or only little internalized the reasons for behavioral enactment. Instead, they act out of external or internal pressure (Deci \& Ryan, 2000). For example, they work hard to be acknowledged by their supervisor, to receive a bonus, or attain job security (i.e. external pressure), or they engage in a particular activity to attain personal pride and ego-enhancement or to avoid guilt, shame, or anxiety (i.e. internal pressure). As no or only a little internalization has taken place, controlled motivation is likely to go along with feelings of pressure and conflict, and, hence suboptimal 
functioning (Deci \& Ryan, 2000).

By way of contrast, SDT considers autonomous motivation to be characterized by an internal perceived locus of causality (Deci \& Ryan, 2000), that is, individuals perceive the reasons for autonomously motivated behavior as emanating from their self and therefore experience volition and psychological freedom when enacting the activity. Individuals act autonomously when they have internalized the reason for enacting the behavior and personally value the activity, as well as when they consider the activity as interesting or enjoyable (Deci \& Ryan, 2000). Employees might work long hours because they value a particular project or because they are completely immersed in a challenging or fascinating task.

According to SDT, adopting an autonomous instead of a controlled regulation yields positive effects in terms of higher well-being and better performance (Ryan \& Deci, 2006). Extant research has validated this assumption (see Gagné \& Deci, 2005; Van den Broeck, Vansteenkiste, \& De Witte, 2008, for overviews). Being autonomously motivated as opposed to being controlled has been positively related to various aspects of employees' well-being, for example, in terms of increased job satisfaction and work engagement (Richer, Blanchard \& Vallerand, 2002), decreased exhaustion and burnout (Fernet, Guay, \& Senécal, 2004), less anxiety (Parker, Jimmieson, \& Amiot, 2010), and physical symptoms (Otis \& Pelletier, 2005). Furthermore autonomous motivation relates positively to (affective) organizational commitment (Gagné, Chemolli, Forest, \& Koestner, 2008), and associates positively with job performance (Bono \& Judge, 2003). Finally, autonomous motivation is positively related to knowledge sharing (Foss, 
Minbaeva Pedersen, \& Reinholt, 2009) and relates negatively to turnover intentions (Milette \& Gagné, 2008).

In the present paper, we argue that the two qualitative types of motivation might help to explain the divergent associations between the two workaholism components and their well-being correlates. Specifically, as outlined in the following paragraphs we suggest that controlled motivation associates with compulsive work, whereas both controlled and autonomous motivation link to excessive work (see Figure 1).

\section{Workaholism and Quality of Motivation}

Various scholars have speculated upon the motivation of workaholics (e.g., Porter, 1996; Schaufeli et al., 2009). First of all, it is suggested that the social environment of workaholics may foster workaholism, and particularly the component of working compulsively, by lauding and praising workaholics' strong work involvement (McMillan, O’Driscoll, \& Burke, 2003; Ng et al., 2007). Workaholics are assumed to be stimulated to gain prestige, peer admiration, and supervisors' approval (Spence \& Robbins, 1992). This is evidenced by workaholics' tendency to pursue work that might result in a pay raise, promotion or other external signs of worth (Porter, 1996). Workaholics might also be negatively reinforced and might escape into their work to avoid unpleasant non-work activities or involvements (Aziz \& Zickar, 2006). In line with this assumption, workaholism has been linked to higher levels of marital estrangement and work-home interference (Aziz \& Zickar, 2006; Taris et al., 2005). Thus, workaholics may feel controlled by their social environment to invest a lot of time and effort in their 
work, even though there are no objective environmental necessities such as deadlines or high financial needs (Taris et al., 2008).

Secondly, working compulsively may also be related to internal pressure, as it is generally agreed that workaholics may consider excessive investment in work as a means to bolster their self-esteem and reduce feelings of guilt, shame or anxiety (e.g., McMillan et al., 2003; Porter, 2004). Support for this view comes from studies showing that working compulsively is positively related to the urge to prove oneself and to perfectionism (Burke, 1999), which, in turn, have been linked to controlled motivation (Miquelon, Vallerand, Grouzet, \& Cardinal, 2005).

Although working compulsively can be reasonably liked with controlled motivation, the motivational pattern driving excessive work may be more complex. We suggest that this quantitative behavioral component of workaholism might result from both controlled and autonomous motivation. Indeed, employees may work long hours out of external or internal pressure (i.e., controlled motivation) as outlined above, but may also volitionally invest many hours in their jobs because they find their work important, interesting or enjoyable (i.e., autonomous motivation). Various studies in the realm of SDT linked autonomous motivation to long-term behavioral persistence. For example, autonomously motivated high school students (Vallerand, Fortier, \& Guay, 1997) and competitive swimmers (Pelletier, Fortier, Vallerand, \& Brière, 2001) have been found to drop out of college and swimming competitions less frequently than their controlled counterparts. When individuals are autonomously stimulated for activities such as recycling or sporting, they are also more likely to freely engage in similar additional 
activities, whereas such persistence is not evident when individuals feel forced to engage in the initial behaviors (Vansteenkiste, Simons, Lens, Sheldon, \& Deci, 2004). When feeling controlled, individuals are likely to persist in a particular activity only for a short, but not a long while (Pelletier et al., 2001) and to experience less interest and enjoyment (Ryan, Koestner, \& Deci, 1991). Building on these results, we argue that working excessively might be fueled by both autonomous and controlled motivation. The motivational base for working excessively, may then drive the impact of working long hours on employees' well-being.

Specifically, as shown in Figure 1, we hypothesize that:

Hypothesis 1: Controlled motivation associates with compulsive work, which, in turn relates positively to exhaustion.

Excessive work, in contrast, may stem from both autonomous and controlled motivation, which results in the following two hypotheses:.

Hypothesis 2a: Controlled motivation is positively associated with excessive work, which in turn relates positively to exhaustion.

Hypothesis 2b: Autonomous motivation is positively associated with excessive work, which in turn relates positively to vigor.

This implies that working compulsively and working excessively may mediate the associations of controlled and autonomous motivation with employees' exhaustion and vigor (Baron \& Kenny, 1986). However, as also other mechanisms may be involved (e.g., Baard et al., 2004), we expect that the workaholism components only partially mediate the relationship between motivation and well-being. 
Method

\section{Procedure}

Data were gathered in Flanders, the Dutch speaking part of Belgium. As part of an introductory course on quantitative research, 76 undergraduate students distributed five questionnaires among friends or relatives with at least three years of working experience. In line with previous research (e.g., Aziz \& Zickar, 2006), only full-time working whitecollar workers were invited to participate. As white-collar workers' responsibilities are generally open ended and not restricted to time and place, they may have both the opportunity and the possibility of engaging in workaholic behaviors (Spence \& Robbins, 1992).

The questionnaires included a cover letter emphasizing that participation was voluntary and anonymous. The completed questionnaires were either picked up by the students in sealed envelopes or sent back to the researchers in pre-stamped envelopes. In total, 370 questionnaires were returned.

\section{Participants}

The sample included somewhat more male (54\%) than female respondents. Participants' age varied between 21 and 60 years $(M=37.95$ years; $S D=11.19$ years $)$. As only white-collar workers were selected, educational level was rather high; $2 \%$ of the participants had completed only primary school, $24 \%$ had left education after secondary school, 54\% had acquired a bachelor's degree, and 21\% had obtained a master's degree. With regard to professional level, $47 \%$ of the respondents were lower level white-collar 
workers, $24 \%$ were professionals (e.g., teachers, nurses), $30 \%$ held a managerial job. Most respondents (93\%) had a permanent job. Participants' working experience within their current employment varied between one month and 38 years $(M=8.95$ years; $S D=$ 9.38 years).

\section{Measurements}

All questionnaires were available in Dutch. Information on the means and standard deviations of the scales can be found in Table 1. The Cronbach's alphas indicate that the internal consistency of all scales was satisfactory (Table 1).

Workaholism was measured using the Dutch Workaholism Scale (DUWAS; Schaufeli et al., 2008), which is based on the Work Addiction Risk Test (Robinson, 1999) and the Workaholism Battery (Spence \& Robbins, 1992). The DUWAS has been previously used to assess workaholism in other Dutch-speaking samples and has shown good internal consistency, and internal and external validity (e.g., Schaufeli et al., 2009). Excessive work included five items such as "I seem to be in a hurry and racing against the clock". Compulsive work included five items such as "It is hard for me to relax when I am not working”. Both scales were scored on a 4-point Likert scale, ranging from 1 ("totally disagree") to 4 ("totally agree").

Exhaustion was measured using the 5-item scale of the Dutch version of the Maslach Burnout Inventory General Survey (Schaufeli \& van Dierendonck, 2000). The participants scored items such as "I feel totally exhausted in my job" on a 7-point Likert scale ranging from 0 ("never") to 6 ("always, every day"). Vigor was assessed via five 
items of the Utrecht Work Engagement Scale (Schaufeli et al., 2002; Van den Broeck, Vansteenkiste, De Witte, \& Lens, 2008). Again the participants indicated on a scale from 0 ("never") to 6 ("always, every day") how often they experienced vigor. A sample item is "At my work, I feel bursting with energy".

Self-Regulation was assessed with 12 items based on the general Self-Regulation Scales of Ryan and Connell (1989). These items were adapted to tap the different regulations for doing one's job, rather than a general regulatory style. Respondents indicated on a scale from 1 ("totally disagree") to 5 ("totally agree") to what extent each of the statements corresponded with their motivations for doing their job. In line with previous research (e.g. Vansteenkiste et al., 2004; Parker et al., 2010) controlled motivation included items such as "because others [partner, parents, friends, ...] expect me to do so" and "because I have to be good in this job, otherwise I would feel disappointed in myself". Autonomous motivation was assessed with items such as "because this job aligns with my personal values" and "because I have fun doing this job".

Plan of Analysis

Following the two-step approach procedure recommended by Anderson and Gerbing (1988), we first tested the divergent validity of our constructs by means of itemlevel confirmatory factor analyses (CFA). We continued by conducting structural equation modeling (SEM) applying the maximum-likelihood method in LISREL 8.54 (Jöreskog \& Sörbom, 2004) to test the hypotheses. Data screening using Prelis 2.71 
(Jöreskog \& Sörbom, 2004) revealed data non-normality at the univariate and multivariate level. Therefore in all subsequent models, in addition to the covariance matrix, the asymptotic covariance matrix was used and the Satorra-Bentler Scaled Chisquare (SBS- $\chi^{2}$; Satorra \& Bentler, 1994) instead of the common Chi-square was inspected. As suggested by $\mathrm{Hu}$ and Bentler (1999), model fit was evaluated, using three goodness of fit indices: The Root Means Square Error of Approximation (RSMEA), the Comparative Fit Index (CFI) and the Standardized Root Means Square Residuals (SRMR). CFI values larger than .95 indicate excellent fit; values larger than .90 indicate good fit (Hoyle, 1995). RSMEA below .05 in combination with SRMR values below .09 indicate excellent fit, whereas values below .08 and .10, respectively, indicate good fit (Byrne, 2001). The chi-square difference test was used to compare the fit of nested models.

To test the hypotheses, following Holmbeck (1997), we first tested the full mediation model in which the hypothesized paths were allowed from autonomous and controlled motivation to working compulsively and working excessively, and from these two workaholism components to exhaustion and vigor. We then tested whether allowing direct relations from autonomous and controlled motivation to employees' well-being resulted in increased model fit (partial mediation model). In all analysis, results were considered to be significant if the accompanying p-value was at least .05 .

Results

\section{Preliminary Analysis}


As shown in Table 1, of the background variables, only age related to the variables under study, that is, it related positively to vigor. As expected, the two workaholism components were positively related. Compulsive work was furthermore positively related to controlled motivation and exhaustion. Excessive work related positively to both controlled and autonomous motivation, as well as to vigor and exhaustion. Whereas controlled motivation associated positively with exhaustion, autonomous motivation related negatively to exhaustion and positively to vigor. As expected, vigor and exhaustion were negatively correlated.

\section{Measurement model}

We estimated a full measurement model including the two types of motivation, the excessive and compulsive component of workaholism, vigor and exhaustion. All variables were presented by their respective items. This model, including 32 observed variables and 6 latent factors, yielded a good fit, $\operatorname{SBS}-\chi^{2}(559)=1131.36, p<.001$; $\mathrm{RSMEA}=.07 ;$ SRMR $=.08$, and CFI $=.93$. All observed variables had significant $(p<$ .001 ) loadings ranging from .48 to .87 on their latent factor (mean $\lambda_{-}=.67$ ). A valid measurement model was thus obtained.

\section{Structural model}

First, we calculated the full mediation model which related controlled and autonomous motivation to working compulsively and working excessively, and the workaholism components to exhaustion and vigor (Baron \& Kenny, 1986). In line with 
previous research, vigor and exhaustion were allowed to correlate (Van den Broeck, Vansteenkiste, De Witte et al., 2008). This model yielded acceptable fit to the data, but showed room for improvement; SBS- $\chi^{2}(456)=1344.31, p<.001 ;$ RSMEA = .07; SRMR $=.13$, and CFI $=.90$.

We therefore computed the partial model in which direct paths from employees' motivation to exhaustion and vigor were added (Figure 2). This model fitted the data well; SBS- $\chi^{2}(454)=1204.31, p<.001 ;$ RMSEA $=.07 ;$ SRMR $=.10$, and CFI $=.92$ and yielded an improved fit compared to the full mediation model; $\Delta \mathrm{SBS}-\chi^{2}(2)=140, p<$ .001. In line with the hypothesis, controlled motivation related positively to both excessive work $(\gamma=.17, p<.05)$ and compulsive work $(\gamma=.48, p<.001)$. As expected, autonomous motivation yielded a direct positive relation with excessive work $(\gamma=.17 ; p$ $<.05)$. As predicted, compulsive work was positively associated with exhaustion $(\gamma=.32$, $p<.001)$, whereas excessive work related positively to vigor $(\gamma=.32, p<.001)$. In addition, autonomous motivation related positively to vigor $(\gamma=.50 ; p<.001)$, and associated negatively with exhaustion $(\gamma=-.46 ; p<.001)$.

Finally, Sobel tests were applied to formally evaluate whether controlled and autonomous motivation yielded indirect associations with exhaustion and vigor through compulsive and excessive work (Sobel, 1982). The indirect relation between controlled motivation and exhaustion through compulsive work $(z=.15, p<.001)$ was confirmed, as was the indirect association between autonomous motivation and vigor $(z=.05, p<$ .05) through excessive work. Notably, from a methodological point of view, this model suggests that an indirect relationship may emerge between controlled motivation and 
vigor through excessive work. Sobel test, however, did not support this relation $(z=.03$, $n s)$.

\section{Discussion}

In this paper, we aimed to further the understanding of workaholism, defined by both a behavioral (i.e., working excessively) and a cognitive (i.e., working compulsively) component (Taris et al., 2008). This two-dimensional definition is in line with the original conceptualization of workaholism (Oates, 1971) and includes the commonly agreed upon workaholism components (Schaufeli et al., 2007). Gaining more insight into workaholism might be important (Sparks et al., 2001), as the incidence of workaholism seems to be increasing (Porter, 2004), and workaholism might yield negative consequences for various stakeholders, including employees, family members and organizations (McMillan, O’Driscoll, \& Brady, 2004).

Specifically, the present study wanted to shed light on the different associations of excessive work and compulsive work with employees' well-being (e.g., Taris et al., 2008). Based on SDT's differentiation between autonomous and controlled motivation, we hypothesized that compulsive work would relate positively to exhaustion because it would originate from controlled motivation (Hypothesis 1). Excessive work was hypothesized to be fueled by both controlled motivation and autonomous motivation and therefore to relate positively to exhaustion (Hypothesis 2a) and vigor (Hypothesis 2b), respectively.

The current findings seem to confirm Hypotheses 1 and 2b. First, as respects 
Hypothesis 1, controlled motivation related positively to compulsive work, which, in turn was positively related to exhaustion. Moreover, compulsive work fully explained the positive association between controlled motivation and exhaustion. These results provide evidence that people work compulsively because they are concerned about extrinsic rewards and punishments, or because they would feel ashamed or guilty when not working, thereby undermining their well-being. Second, as expected in Hypothesis 2, both autonomous and controlled motivation related positively to the tendency to work excessively. Excessive work, furthermore, partially explained the association between autonomous motivation and vigor. These findings provide support for Hypothesis $2 b$ that working long hours may be energizing rather than depleting, when people find their work useful and interesting.

Unexpectedly, despite the correlation between excessive work and exhaustion, these concepts did not yield a significant structural relation, after controlling for compulsive work. Accordingly, indirect effects of controlled motivation on employees' exhaustion through excessive work did not emerge. Hypothesis $2 b$ was therefore not corroborated. Perhaps, the relationship between excessive work and exhaustion might be attenuated by a restriction of range in excessive work in the present study. Previously it has been suggested that only fairly high levels of overtime would be health-impairing (Beckers et al., 2004). Alternatively, the weak relation between excessive work and exhaustion might perhaps be attributed to qualitative, rather than quantitative, differences in overtime, hinting at moderating variables such as the quality of work (Beckers et al., 2004). 
In sum, the present results suggest that working compulsively is likely to have health-impairing correlates since it is fuelled by a qualitatively poor type of motivation. Working excessively, on the other hand, may not be related to ill-health in the event that it is driven by a qualitatively good type of motivation.

\section{Theoretical and practical implications}

The present findings contribute to the literature on workaholism in several ways.

First, this study adds to the understanding of the motivation of workaholics. Although this topic is widely discussed in the literature (e.g., Burke \& Matthiesen, 2004; Spence \& Robbins, 1992), it has not yet been fully empirically or theoretically substantiated. Workaholics are generally assumed to be highly motivated (e.g., $\mathrm{Ng}$ et al., 2007). The present findings, however, indicate that their motivation might, in part, be of inferior quality, thereby possibly resulting in suboptimal functioning. Second, our findings seem to confirm that working excessively is a necessary but not sufficient condition of succumbing the syndrome of workaholism. Excessive work may be motivated by various reasons, both autonomous and controlled. In the former case, it relates positively to wellbeing, as is hypothesized in SDT. This conforms that excessive work might in itself not be negative, a suggestion that was previously made in a large scale study on long working hours (Beckers et al., 2004). Working compulsively, however, relates positively to health-impairment. The health-impairing associations of workaholism might thus primarily be attributed to working compulsively, as was previously suggested by Taris and colleagues (2008). 
The present findings may also add to SDT. They confirm, once more, that autonomous motivation relates positively and controlled motivation relates negatively to optimal functioning, that is, employees' work related well-being in terms of decreased exhaustion and increased vigor (e.g., Judge, Bono, Erez, \& Locke, 2005). Interestingly, these findings indicate that autonomous motivation may hold strong direct associations with both well-being and ill-health, whereas controlled motivation may relate, less strongly, to employees' well-being via other aspects of employee functioning such as compulsive work.

At the practical level, results suggest that practitioners might primarily focus on decreasing workaholics' tendency to work compulsively. This might be achieved, for instance, by creating a growth culture rather than a pressurizing culture (Buelens \& Poelmans, 2004) or by decreasing job demands (e.g., work pressure, role conflicts and emotional demands) and increasing job resources (e.g., job control and social support; Johnstone \& Johnson, 2005; Schaufeli et al., 2007; 2008).

The present findings furthermore confirm that the quality of motivation matters. That is, highly motivated employees may either experience well-being and function optimally, or lack well-being and develop problematic attitudes towards work, depending on the type of regulation underlying their behavior. Practitioners might therefore aim to stimulate in employees autonomous rather than controlled motivation. According to SDT, this may be achieved by adopting an autonomy supportive style which is characterized by being empathic and offering choice and by providing rationales if choice is restricted. Previous research supported that such an interaction style may foster autonomous 
motivation in others (e.g., Otis \& Pelletier, 2005; Senécal, Vallerand, \& Guay, 2001).

\section{Limitations and Suggestions for further research}

This study is not without limitations. First, as the present sample does not necessarily provide an accurate view of the prevalence of workaholism in the population, future studies might aim to focus on the prevalence of workaholism. The primary aim of the current study was, however, to study the associations between workaholism and employees' functioning. The current sample seemed suitable for this end, as the mean levels of excessive and compulsive work in the present sample are comparable to those of the samples employed in similar studies (e.g., Schaufeli et al., 2009).

Second, as all data were gathered through self-reports, common method variance might have increased the strength of the observed relationships. However, as similar results have been found for both workaholics' and acquaintances' ratings (e.g., Aziz \& Zickar, 2006; McMillan, O’Driscoll et al., 2004), we do not expect the use of self-reports to significantly downplay our results. Furthermore, self-ratings seem to be the most feasibly way to assess individuals' workaholism, as acquaintances seem to underestimate workaholics' tendency to work compulsively (McMillan, O’Driscoll et al., 2004).

Third, because of the present study's cross-sectional design, the causal order between workaholism, motivation and well-being remains to be addressed. Possibly, workaholism and the different types of motivation might influence well-being over time. Alternatively, workers' levels of well-being might set the conditions for workaholism and autonomous versus controlled motivation to emerge. Individuals who feel vigorous, satisfied or efficacious in their jobs might, for instance, have the energy to work long 
hours and seek out important, fun or interesting tasks (de Lange, De Witte, \& Notelaers, 2008).

Similarly, the dynamic interplay between employees' motivation and workaholism remains to be studied. The present study conceptualizes autonomous and controlled motivation as drivers of workaholism, as motivation refers to a more general orientation towards one's job, whereas workaholism might be considered a more specific attitude towards work. Although no conclusions about causality can be drawn, the current study nonetheless contributes to our understanding of workaholism, as it shows that working compulsively and working excessively are associated with qualitatively different types of work motivation.

\section{Conclusions}

In sum, the present study adds to the understanding of workaholism by disentangling the positive and negative well-being associates of the two workaholism components, that is, working excessively and working compulsively (Taris et al., 2008). The present research furthermore helps to understand workaholics' motivation from a theoretical point of view and therefore answers the calls for a theoretically based approach in the study of workaholism (e.g., McMillan et al., 2001). In general, the findings seem to suggest that the propensity to work compulsively relates to ill-health (i.e. exhaustion) because it is associated with feelings of coercion (i.e. controlled motivation). Excessive work, by way of contrast, is accompanied by experiences of joy and interest or awareness of the significance of their job (i.e. autonomous motivation) and therefore associates positively with workers' well-being (i.e. vigor). 


\section{References}

Aziz, S. \& Zickar, M. J. (2006). A cluster analysis investigation of workaholism as a syndrome. Journal of Occupational Health Psychology, 11, 52-62.

Anderson, J. C., \& Gerbing, D. W. (1988). Structural equation modeling in practice: A review and recommended two-step approach. Psychological Bulletin, 103 (3), 411-423.

Baard, P., Deci, E. L, \& Ryan, R. M. (2004). Intrinsic need satisfaction: A motivational basis of performance and well-being in two work settings. Journal of Applied Social Psychology, 34, 2045-2068.

Baron, R. M., \& Kenny, D. A. (1986). The moderator-mediator variable distinction in social psychological research: Conceptual, strategic and statistical considerations. Journal of Personality and Social Psychology, 51, 1173-1182.

Barrett, L. F., Mesquita, B., Ochsner, K. N., \& Gross, J. J. (2007). The experience of emotion. Annual Review of Psychology, 58, 373-403.

Beckers, D. G. J., van der Linden, D., Smulders, P. G. W., Kompier, M. A. J., van Veldhoven, M. J. P. M., \& van Yperen, N.W. (2004). Working overtime hours: Relations with fatigue, work motivation, and the quality of work. Journal of Occupational and Environmental Medicine, 46, 1282-1289.

Bono, J. E., \& Judge, T. A. (2004). Personality and transformational and transactional leadership: A meta-analysis. Journal of Applied Psychology, 89, 901-910.

Brett, J. M., \& Stroh, L. K. (2003). Working 61 plus hours a week: Why do managers do it? Journal of Applied Psychology, 88, 67-78. 
Brown, S. P., Cron, W. L., \& Slocum, Jr., J. W. (1997). Effects of goal-directed emotions on salesperson volition, behavior, and performance: A longitudinal study. Journal of Marketing, 61, 39-50.

Buelens, M., \& Poelmans, S. A. Y. (2004). Enriching the Spence and Robbins' typology of workaholism: Demographic, motivational and organizational correlates. Organizational Change Management, 17, 459-470.

Burke, R. J. (1999). It's not how hard you work but how you work hard: Evaluating workaholism components. International Journal of Stress Management, 6, 225239.

Burke, R. J. (2001). Workaholism in organizations: the role of organizational values. Personnel Review, 30, 637-645.

Burke, R. J., \& Matthiesen, S. (2004). Workaholism among Norwegian journalists: Antecedents and consequences. Stress \& Health, 20, 301-308.

Burke, R. J., Matthiesen, S. B., \& Pallesen, S. (2006). Personality correlates of workaholism. Personality and Individual Differences, 40, 1223-1233.

Byrne, B. M. (2001). Structural equation modelling with Amos. Basic concepts application and programming. Mahwah, NJ: Lawrence Erlbaum Associates. .

deCharms, R. (1968). Personal causation: The internal affective determinants of behavior. New York: Academic Press.

Deci, E. L., \& Ryan, R. M. (2000). The "what" and "why" of goal pursuits: Human needs and the self-determination of behavior. Psychological Inquiry, 11, 319-338.

de Lange, A. H., De Witte, H., \& Notelaers, G. (2008). Should I stay or should I go? 
Examining longitudinal relations among job resources and work engagement for stayers versus movers. Work \& Stress, 22, 201-223.

Demerouti, E., Mostert, K., \& Bakker, A. B. (2010). Burnout and work engagement: A thorough investigation of the independency of both constructs. Journal of Occupational Health Psychology, 15, 209-222.

De Witte, H., \& De Cuyper, N. (2003). Naar een positieve benadering van "werkstress": op zoek naar "bevlogenheid" bij Vlaamse werknemers. [Towards a positive approach on job stress: In search of work engagement among Flemish employees]. Paper presented at the Arbeidsmarktonderzoekersdag, May, 2003, VUB-Brussel.

Fernet, C., Guay, F., \& Senécal, C. (2004). Adjusting to job demands: The role of work self-determination and job control in predicting burnout. Journal of Vocational Behaviour, 65, 39-56.

Fisher, C. D., \& Noble, C. S. (2004). A within-person examination of correlates of performance and emotions while working. Human Performance, 17, 145-168.

Foss, N. J., Minbaeva, D. B., Pedersen, T., \& Reinholt, M. (2009). Encouraging knowledge sharing among employees: How job design matters. Human Resource Management, 48, 871-893.

Gagné, M., Chemolli, E., Forest, J., \& Koestner, R. (2008). A temporal analysis of the relation between organisational commitment and work motivation. Psychologica Belgica, 48-2\&3, 219-241.

Gagné, M., \& Deci, E. L. (2005). Self-determination theory and work motivation. 
Journal of Organizational Behaviour, 26, 331-362.

Holmbeck, G. N. (1997). Toward terminological, conceptual, and statistical clarity in the study of mediators and moderators: Examples from the child-clinical and pediatric psychology literatures. Journal of Consulting and Clinical Psychology, 65, 599610.

Hoyle, R. H. (1995). Structural equation modeling: Concepts, issues, and applications. Thousand Oaks, CA: Sage Publications.

Hu, L., \& Bentler, P. M. (1999). Cutoff criteria for fit indexes in covariance structure analysis: Conventional criteria versus new alternatives. Structural Equation Modelling, 6, 1-55.

Johnstone, A., \& Johnson, L. (2005). The relationship between organizational climate, occupational type and workaholism. New Zealand Journal of Psychology, 34, 181-188.

Jöreskog, K. G., \& Sörbom, D. (2004). LISREL 8.7 User's Reference Guide. Chicago: Scientific Software International.

Judge, T. A., Bono, J. E., Erez, A., \& Locke, E. A. (2005). Core self-evaluations and job and life satisfaction: The role of self-concordance and goal attainment. Journal of Applied Psychology, 90, 257-268.

Kinnunen, U., Feldt, T., \& Mäkikangas, A. (2008). Testing the effort imbalance model among Finnish managers: The role of perceived organizational support. Journal of Occupational Health Psychology, 13, 114-127.

Maslach, C., Schaufeli, W. B., \& Leiter, M. (2001). Job burnout. Annual Review of 
Psychology, 52, 397-422.

McMillan, L. H. W., \& O’Driscoll, M. P. (2004). Workaholism and health: Implications for organizations. Journal of Organizational Change Management. 17, 509-519.

McMillan, L. H. W., O'Driscoll, M. P., \& Brady, E. C. (2004). The impact of workaholism on personal relationships. British Journal of Guidance \& Counselling, 32, 171-186.

McMillan, L. H. W., O’Driscoll, M. P., \& Burke, R. J. (2003). Workaholism: A review of theory, research, and future directions. International Review of Industrial and Organizational Psychology, 18, 167-189.

McMillan, L. H. W., O’Driscoll, M. P., Marsh, N. V., \& Brady, E. C. (2001). Understanding workaholism: Data synthesis, theoretical critique, and future design strategies. International Journal of Stress Management, 8, 69-91.

Milette, V. \& Gagné, M. (2008). Designing volunteers' tasks to maximize motivation, satisfaction and performance: The impact of job characteristics on the outcomes of volunteer involvement. Motivation and Emotion, 32, 11-22.

Miquelon, P., Vallerand, R. J., Grouzet, F. M. E., \& Cardinal, G. (2005). Perfectionism, academic motivation, and psychological adjustment: An integrative model. Personality and Social Psychology Bulletin, 31, 913-924.

Mudrack, P. E., \& Naughton, T. J. (2001). The assessment of workaholism as behavioral tendencies: Scale development and preliminary empirical testing. International Journal of Stress Management, 8, 93-111.

Ng., T. W. H., Sorensen, K. L., \& Feldman, D. C. (2007). Dimensions, antecedents, and 
consequences of workaholism: a conceptual integration and extension. Journal of Organizational Behavior, 28, 111-136.

Oates, W. (1971). Confessions of a workaholic: The facts about work addiction. New York: World.

Otis, N., \& Pelletier, L. G. (2005). A motivational model of daily hassles, physical symptoms, and future work intentions among police officers. Journal of Applied Social Psychology, 35, 2193-2214.

Parker, S. L., Jimmieson, N. L., \& Amiot, C. E. (2010). Self-determination as a moderator of demands and control: Implications for employee strain and engagement. Journal of Vocational Behavior, 76, 52-67.

Pelletier, L. G., Fortier, M. S., Vallerand, R. J., \& Brière, N. M. (2001). Associations among perceived autonomy support, forms of self-regulation, and persistence: A prospective study. Motivation and Emotion, 25, 279-306.

Porter, G. (1996). Organizational impact of workaholism: Suggestions for researching the negative outcomes of excessive work. Journal of Occupational Health Psychology, 1, 70-84.

Porter, G. (2004). Work, work ethic, work excess. Journal of Organizational Change Management, 17, 424-439.

Richer, S. F., Blanchard, C., \& Vallerand, R. J. (2002). A motivational model of work turnover. Journal of Applied Social Psychology, 32, 2089-2113.

Robinson, B. E. (1999). The Work Addiction Risk Test: Development of a tentative measure of workaholism. Perceptual and Motor Skills, 88, 199-210. 
Ryan, R. M., \& Connell, J. P. (1989). Perceived locus of causality and internalization: Examining reasons for acting in two domain. Journal of Personality and Social Psychology, 57, 749-761.

Ryan, R. M., \& Deci , E. L. (2006). Self-regulation and the problem of human autonomy: Does psychology need choice, self-determination, and will? Journal of Personality, 74, 1557-1585.

Ryan, R. M., \& Deci, E. L., (2001). On happiness and human potentials: A review of research on hedonic and eudaimonic well-being. Annual Review of Psychology, $52,141-166$.

Ryan, R. M., Koestner, R., \& Deci, E. L. (1991). Ego-involved persistence: When freechoice behavior is not intrinsically motivated. Motivation and Emotion, 15, 185205.

Satorra, A., \& Bentler, P. M. (1994). Corrections to test statistics and standard errors in covariance structure analysis. In A. von Eye \& C. C. Clogg (Eds.), Latent variables analysis: Applications for developmental research (pp. 399-419). Thousand Oaks, CA: Sage.

Schaufeli, W. B., \& van Dierendonck, D. (2000) Utrechtse Burnout Schaal (UBOS): Testhandleiding. Amsterdam: Harcourt Test Services.

Schaufeli, W. B., Salanova, M., Gonzalez-Roma. V., \& Bakker, A. B. (2002). The measurement of engagement and burnout and: A confirmative analytic approach. Journal of Happiness Studies, 3, 71-92.

Schaufeli, W. B., Shimazu, A., \& Taris, T. W. (2009). Being driven to work excessively 
hard. The evaluation of a two-factor measure of workaholism in the Netherlands and Japan. Cross-Cultural Research, 43, 320-348.

Schaufeli, W. B., Taris, T. W., \& Bakker, A. B. (2008). It takes two to tango. Workaholism is working excessively and working compulsively. In R. J. Burke \& C. L. Cooper (Eds.), The long work hours culture. Causes, consequences and choices (pp. 203-226). Bingley U.K.: Emerald.

Schaufeli, W. B., Taris, T. W., \& Bakker, A. B. (2006). Dr. Jekyll and Mr. Hide: On the differences between work engagement and workaholism. In: R. Burke (Ed.), Work hours and work addiction. (pp. 193-252). Northhampton, UK: Edward Elgar.

Schaufeli, W. B., Taris, T. W., \& Van Rhenen, W. (2007). Workaholism, burnout and engagement Three of a kind or three different kinds of employee well-being. Applied Psychology: An International Review, 57, 173-203.

Scott, K. S., Moore, K. S., \& Miceli, M. P. (1997). An exploration of the meaning and consequences of workaholism. Human Relations, 50, 287-314.

Senécal, C., Vallerand, R. J., \& Guay, F. (2001). Antecedents and outcomes of workfamily conflict: Toward a motivational model. Personality and Social Psychology Bulletin, 27, 176-186.

Snir, R., \& Harpaz, I. (2006). The workaholism phenomenon: A cross-national perspective. Career Development International, 11, 374-393.

Snir, R., \& Zohar, D. (2007). Workaholism as discretionary time investment at work: An experience sampling study. Applied Psychology: An international Review, 57, 109-127. 
Sobel, M. E. (1982). Asymptotic intervals for indirect effects in structural equations models. In S. Leinhart (Ed.), Sociological methodology (pp. 290-312). San Francisco: Jossey-Bass.

Sparks, K., Faragher, E.B., \& Cooper, C.L. (2001). Well-being and occupational health in the 21 st century workplace. Journal of Occupational and Organizational Psychology, 74, 489-510.

Spence, J. T., \& Robbins, A. S. (1992). Workaholism: Definition, measurement, and preliminary results. Journal of Personality Assessment, 58, 160-178.

Taris, T. W., Geurts, S. A. E., Schaufeli, W. B., Blonk, R. W. B., \& Lagerveld, S. E. (2008). All day and all of the night: The relative contribution of two dimensions of workaholism to well-being in self-employed workers. Work and Stress, 22, 153-165.

Taris, T. W., Schaufeli, W. B., \& Verhoeven, L. C. (2005). Internal and external validation of the Dutch Work Addiction Risk Test: Implications for jobs and nonwork conflict. Journal of Applied Psychology: An international Review, 54, 3760.

Taris, T. W., Ybema, J. F., Beckers, D. G. J., Verheijden, M. W., Geurts, S. A. E., \& Kompier, M. A. J. (in press). Investigating the associations among overtime work, health behaviors, and health: A longitudinal study among full-time employees. International Journal of Behavioral Medicine.

Vallerand, R. J., Fortier, M. S., \& Guay, F. (1997). Self-determination and persistence in a real-life setting: Toward a motivational model of high school dropout. Journal 
of Personality and Social Psychology, 75, 1161-1176.

Van den Broeck, A., Vansteenkiste, M., \& De Witte, H. (2008). Self-determination theory: A theoretical and empirical overview in occupational health psychology. In J. Houdmont \& S. Leka (Eds.). Occupational health psychology: European perspectives on research, education, and practice. Vol. 3. (pp. 63-88). Nottingham: Nottingham University Press.

Van den Broeck, A., Vansteenkiste, M., De Witte, H., \& Lens, W. (2008). Explaining the relationships between job characteristics, burnout and engagement: The role of basic psychological need satisfaction. Work \& Stress, 22, 277-294.

Vansteenkiste, M., Simons, J., Lens, W., Sheldon, K. M., \& Deci, E. L. (2004). Motivating learning, performance, and persistence: The synergistic role of intrinsic goals and autonomy-support. Journal of Personality and Social Psychology, 87, 246-260.

Vroom, V. (1964). Work and motivation. New York: Wiley. 
Table 1

Means, Standard Deviations, Alphas and Correlations among all studied variables.

\begin{tabular}{|c|c|c|c|c|c|c|c|c|c|c|c|}
\hline & Mean & SD & 1. & 2. & 3. & 4. & 5. & 6. & 7. & 8. & 9. \\
\hline 1. Gender & 1.47 & .55 & & & & & & & & & \\
\hline 2. Age & 37.95 & 11.19 & $-.11 *$ & & & & & & & & \\
\hline 3. Educational level & 5.69 & 1.24 & -.05 & -.06 & & & & & & & \\
\hline 4. Compulsive Work & 2.08 & .62 & .09 & .00 & .00 & $(.77)$ & & & & & \\
\hline 5. Excessive Work & 2.55 & .59 & -.05 & .03 & .04 & $.48^{* *}$ & $(.71)$ & & & & \\
\hline 6. Controlled Motivation & 2.53 & .68 & .03 & -.06 & -.03 & $.38 * *$ & $.12 *$ & $(.78)$ & & & \\
\hline 7. Autonomous Motivation & 3.69 & .69 & .07 & -.01 & -.01 & -.08 & $.11 *$ & -.01 & $(.88)$ & & \\
\hline 8. Vigor & 4.23 & .96 & -.02 & $.17 * *$ & -.01 & .04 & $.32 * *$ & -.02 & $.57 * *$ & $(.85)$ & \\
\hline 9. Exhaustion & 1.91 & 1.05 & .00 & -.01 & .02 & $.33 * *$ & $.17 * *$ & $.19 * *$ & $-.40 * *$ & $-.40 * *$ & $(.85)$ \\
\hline
\end{tabular}

Note: $* \mathrm{p}<.05 ; * * \mathrm{p}<.01 ; * * * \mathrm{p}<.001$ 
Figures

Figure 1. Theoretical Model of the Associations between Autonomous and Controlled Motivation Workaholism, Well-being and Performance.

Figure 2. Structural Model of the Relationships between Autonomous and Controlled Motivation, Workaholism and Well-being and Performance. Coefficients represent standardized estimates.

$* p<.05 ; * * p<.01 ; * * * p<.001$ 
Figure 1

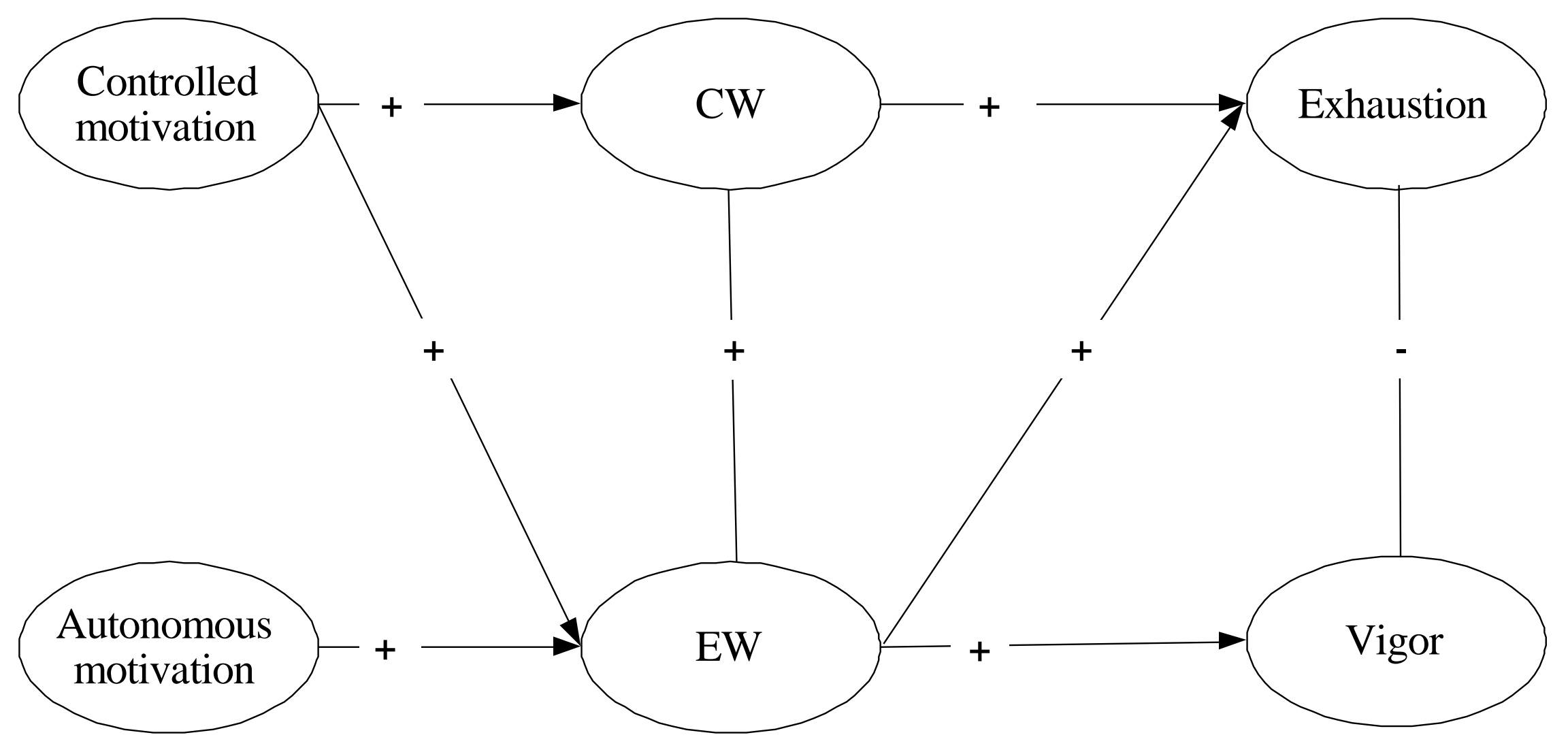


Figure 1

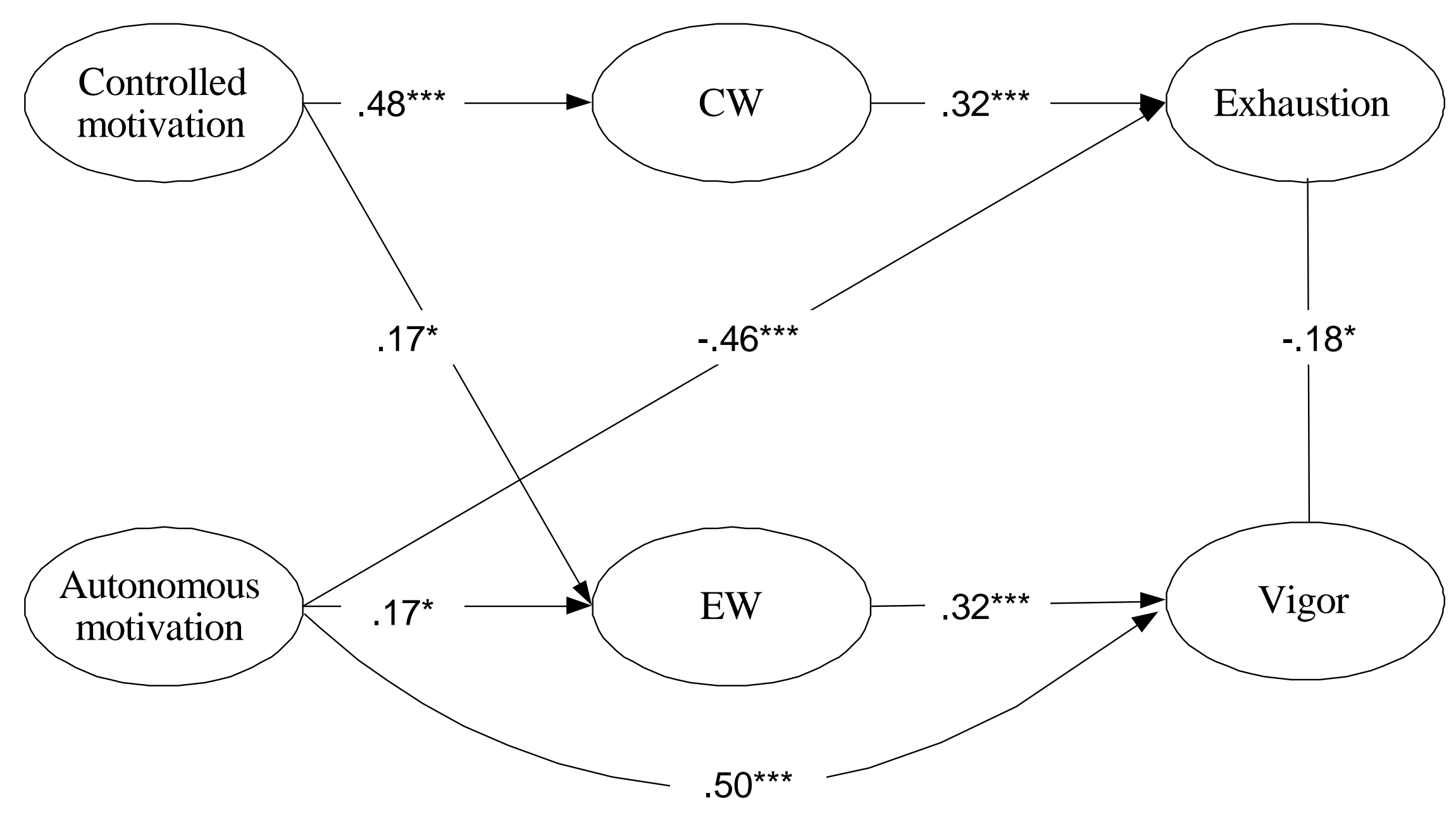

